\title{
Implante imediato com uso da membrana de polipropileno: Relato de caso
}

\author{
Thais de Oliveira Cavestro ${ }^{1}$, Evan Novais de Oliveira², Larissa Ledo Pereira Santana³.
}

Resumo: A reabilitação oral com implantes dentários se tornou uma alternativa de tratamento com significativa previsibilidade. A possibilidade da colocação imediata de implantes após extração dental tem se tornado um tratamento cada vez viável nos consultórios odontológicos, por simplificar o tratamento, minimizando o tempo de cicatrização e reduzindo o custo, trazendo mais conforto ao paciente, além de preservação dos tecidos moles e duros. A instalação de membranas impermeáveis (Bone Heal®) 100\% constituídas de polipropileno em pósexodontias está sendo proposta com a finalidade de promover o isolamento da área a ser regenerada. Ela exerce a função de barreira mecânica, impedindo o crescimento epitelial e conjuntivo. O presente artigo tem como objetivo apresentar um relato de caso clínico no qual foi realizada a instalação imediata de implante em alvéolo sadio e o uso da técnica de regeneração óssea guiada através da membrana de polipropileno.

Palavras-chave: Implante imediato, membrana de polipropileno, Bone Heal.

\section{Immediate implant with use of polypropylene membrane: Case report}

\begin{abstract}
Dental rehabilitation with dental implants has become a treatment alternative with significant predictability. The possibility of immediate placement of implants after dental extraction has become an increasingly sought after treatment in dental offices for simplifying treatment, minimizing healing time, reducing cost and bringing comfort to the patient, as well as soft tissue preservation and hard The installation of $100 \%$ waterproof membranes (Bone Heal®) made of polypropylene in post-extraction is being proposed with the purpose of promoting the isolation of the area to be regenerated by exerting the mechanical barrier function, preventing epithelial and connective growth, and the material of graft then acts as the osteoconductor. The present article aims to present a case report in which the immediate implantation of a healthy alveolus was performed and the use of bone regeneration technique guided through the polypropylene membrane.
\end{abstract}

Keywords: Immediate implant, polypropylene membrane, Bone Heal.

\footnotetext{
${ }^{1}$ Graduanda em Odontologia pela Faculdade Independente do Nordeste, Vitória da Conquista, Bahia, Brasil.

Contato: thaiscavestro@hotmail.com;

${ }^{2}$ Mestrado Profissional em Radiologia Odontológica e Imaginologia pelo Centro de Pesquisas Odontológicas São Leopoldo Mandic, Brasil(2013). Professor do curso de Odontologia da Faculdade Independente do Nordeste , Vitória da Conquista, Brasil;

3Professora do curso de Odontologia da Faculdade Independente do Nordeste. Cirurgiã-dentista mestre e especialista na área de Implantodontia pela ABO-MG.
}

1098 Id on Line Rev. Mult. Psic. V.12, N. 42, p. 1098-1109, 2018 - ISSN 1981-1179 Edição eletrônica em http://idonline.emnuvens.com.br/id 


\section{Introdução}

Nas últimas décadas a implantodontia moderna além de apresentar um crescente progresso tecnológico, possui custo/benefício e tempo satisfatórios, preserva altura, espessura óssea alveolar, dimensão do tecido mole ${ }^{1}$, um posicionamento tridimensional ideal e satisfação do paciente tratado 2 . Por outro lado, a presença de patologia periapical, a ausência de tecido queratinizado, o biótipo de tecido fino e a falta de fechamento completo dos tecidos moles sobre o sítio da extração têm sido relatados como adversos nos implantes colocados imediatamente ${ }^{3},{ }^{4}$.

Estudos clínicos tem demonstrado que o prognóstico dos implantes imediatos é similar aos dos implantes instalados convencionalmente após a cicatrização, com um índice de êxito de $92,7 \%-98 \%{ }^{5}$. A técnica do implante imediato consiste em um mesmo ato cirúrgico realizar a extração do elemento indicado, com a máxima preservação dos tecidos ósseos ${ }^{6,7}$, e a inserção do implante, sem esperar que haja o tempo de espera de cicatrização do sítio ${ }^{8}$.

Para determinar o sucesso clínico não deve apresentar dor, sinais de infecção ou mobilidade e radiograficamente deve-se observar a osseointegração, ou seja, a ausência de um halo radiolúcido peri-implantar ${ }^{9,10}$. Visando a preservação da sua anatomia e do volume ósseo alveolar $^{11}$, vários pesquisadores indicam a realização de métodos regenerativos para a manutenção da crista óssea com a utilização de biomateriais ${ }^{12}$. Assim, a utilização da membrana de polipropileno tem sido uma boa opção, e vem mostrando resultados bastante satisfatórios.

A membrana de polipropileno Bone Heal® é um material biocompatível, onde a superfície interna apresenta rugosidades que a mantém em posição pelo processo de coagulação do sangue, é resistente, permite a regeneração conjunta de tecido ósseo e tecido queratinizado, adesão do tecido sem mobilidade e bloqueio do tecido mole em crescimento ${ }^{13}$. A principal vantagem dessa membrana é que suas superfícies são impenetráveis às bactérias, o que significa que ela pode ser deixada exposta durante o período de cicatrização ${ }^{14}$.

Com o advento das membranas, surge o conceito de Regeneração óssea Guiada (ROG) que vem sendo empregada para que o tecido conjuntivo e epitelial não invada o alvéolo no período de cicatrização ${ }^{15}$. Nesse momento é fundamental o isolamento do coágulo sanguíneo no alvéolo, a preservação de osteoblastos vivos e contato do coágulo com tecido ósseo vivo ${ }^{16}$, que posteriormente será substituído por tecido de granulação e restringirá a infiltração do tecido epitelial ${ }^{17}$. Para garantir que a ROG seja bem sucedida, quatro princípios devem ser cumpridos: 
exclusão do epitélio e tecido conjuntivo, manutenção espacial, estabilidade do coágulo de fibrina e fechamento primário da ferida ${ }^{18}$.

O coágulo sanguíneo é primordial para o processo de reparação óssea, pois além de ser rico em suprimento de plaquetas e proteínas morfogenéticas ósseas ${ }^{19}$, é também um dos fatores de crescimento que propiciam a regeneração óssea alveolar ${ }^{15}$. Consequentemente forma-se uma rede de fibrina que fornece resistência. Usando assim uma barreira de polipropileno não reabsorvível e totalmente impermeável, permite as células indiferenciadas do coágulo produzam tecido ósseo, sem que haja penetração de tecido epitelial e conjuntivo, não havendo necessidade de dispositivos de fixação ${ }^{20}$.

É fundamental que ela fique exposta, podendo ser removida de 7 a 14 dias $^{21}$. Os resultados de neoformação óssea ocorrem em aproximadamente 3 a 4 meses, sendo capaz de ser feito a extração, o implante e o ROG simultaneamente, em um mesmo ato cirúrgico ${ }^{19}$.

Portanto, é objetivo deste artigo é demonstrar, por meio um caso clínico, os principais fatores para obtenção do sucesso na instalação de implante imediato e avaliar a neoformação óssea na utilização da membrana não absorvível de polipropileno, exposta ao meio bucal com a finalidade de conter o coágulo sanguíneo.

\section{Relato do Caso Clínico}

Paciente de 61 anos, gênero masculino, leucoderma, compareceu ao consultório odontológico da cidade de Vitória da Conquista, Bahia, apresentando lesão cariosa extensa com comprometimento de furca no elemento dentário 16, que fora confirmada no exame de tomografia computadorizada volumétrica cone beam, sendo indicada a remoção cirúrgica desse dente e fixação de um implante imediato, pois havia remanescente ósseo suficiente.

Durante anamnese, paciente apresentou-se assintomático, sem presença de dor. Foi solicitado exames laboratoriais (hemograma, coagulograma e glicemia), no qual verificou-se que o paciente era ASA-2 (condição de doença sistêmica leve ou moderada, sem limitação funcional).

Uma vez que o prognóstico para a instalação imediata do implante pós -exodontia foi considerado apropriado aos exames diagnósticos. O paciente foi medicado 1 hora antes da 
cirurgia com 4 miligramas de amoxicilina, como forma de profilaxia antibiótica. Foi realizada a antissepsia extra-oral com clorexidina a $2 \%$ e intra-oral com clorexidina $0,12 \%$. O ato cirúrgico foi sob anestesia local, realizou-se o bloqueio do nervo alveolar superior posterior, palatino menor e intrapapilar no elemento 16 , utilizando lidocaína $2 \%$ com epinefrina 1.100 .00 .

O procedimento foi realizado com o mínimo de trauma possível, tendo em vista conservar a estrutura óssea circunjacente. $\mathrm{O}$ alvéolo foi inspecionado, e todas as tábuas ósseas alveolares estavam intactas. Optou-se e pela colocação de um implante de 4,1 mm de diâmetro por $8 \mathrm{~mm}$ de comprimento (STRAUMANN SLACTVE), na crista alveolar. Foi alcançada uma ótima estabilidade primária após a conclusão do procedimento cirúrgico. Houve a curetagem do alvéolo ósseo remanescente para formar coágulo imediatamente após a exodontia. Em seguida foi realizada contenção com barreira de polipropileno (BONE HEAL).

Ao finalizar a cirurgia, foi prescrito Amoxicilina $500 \mathrm{mg}$, de $8 \mathrm{em} 8$ horas, durante 7 dias, Nimesulida $100 \mathrm{mg}$, de $12 \mathrm{em} 12$ horas, por 5 dias e Tylex $30 \mathrm{mg}, 5 \mathrm{em} 5$ horas, por 2 dias.

Após o período de dois meses foi realizada a reabilitação definitiva com prótese sobre implante e em seis meses, ocorreu a consulta de preservação e radiografia de controle.

\section{Discussão}

A função dentária perdida, após a exodontia, pode ser reabilitada através da instalação de implantes, onde a realização deste imediatamente após o processo de extração, como relatado por autores ${ }^{1,3,5}$ tem apresentado maior grau de satisfação por parte dos pacientes, uma vez que os mesmos são submetidos a uma quantidade menor de procedimentos cirúrgicos.

Nesse caso clínico, a instalação do implante de imediato à extração dentária foi possível pois havia quantidade e qualidade óssea satisfatórias na região apical do alvéolo, apesar da existência da lesão de furca, fato este que está de acordo com estudos disponíveis na literatura ${ }^{11,13,14}$.

Como descrito por alguns autores ${ }^{3,7}$ o procedimento de instalação do implante imediatamente após a exodontia dentária visa a preservação da altura e espessura óssea, além 
de reduzir o tempo cirúrgico e custos do tratamento, também conserva o formato da gengiva, fato que é de grande valia para o sucesso estético da futura reabilitação protética

Quanto a estabilidade do implante foi discutido, que é condizente com as características apresentadas em implantes instalados tardiamente, após 3 a 4 meses ${ }^{9,10}$.

Alguns autores ${ }^{6,9}$ relatam que a instalação do implante imediatamente após o processo de extração cirúrgica requer um período maior de osseointegração, e que este tempo é diretamente relacionado com a estabilidade primária alcançada no momento da colocação do mesmo, onde aqueles que apresentam uma boa estabilidade podem receber carga mastigatória dentro de 2 a 3 meses, e os demais requerem uma espera maior, de aproximadamente 4 meses.

De acordo com Haddad $^{3}$ e colaboradores, o crescente aumento na preocupação dos profissionais frente a necessidade de manutenção dos rebordos alveolares, e minimização da reabsorção óssea sofrida após as extrações tem promovido uma maior prática da técnica de Regeneração Tecidual e Óssea Guiada, na qual visa favorecer a proliferação de células ósseas no interior do alvéolo. Entretanto, como apresentado por MUNIR \& SIQUEIRA ${ }^{22}$, apesar da prática recorrente de tal técnica a mesma na maioria das vezes requer o uso de materiais de enxerto para preenchimento do alvéolo, o que pode onerar os custos do tratamento ${ }^{20}$.

Um aspecto bastante debatido na literatura é o tamanho da lacuna em relação ao uso ou não de biomateriais para a prática da regeneração tecidual guiada. Onde pode ser observado que um gap marginal, ocorrido entre o tecido ósseo e a superfície do implante após uma extração e a instalação imediata, pode cicatrizar com a neoformação óssea o que consequentemente promove a resolução desse defeito ósseo $0^{3,5,67,15-17}$. E que um gap marginal amplo e fundo, localizado nas faces vestibular e palatina, poderia ser resolvido através da neoformação óssea dentro da lacuna, fato este no qual concordam outros autores ${ }^{15,17,20,23}$, onde descrevem que o defeito marginal gerado após a realização do implante imediato em região pós-extração pode cicatrizar sem o uso de barreira ou material de preenchimento. Corroborando com os demais autores $^{1,2,4,6}$, estudos recentes confirmaram que até em casos de defeitos maiores que $4 \mathrm{~mm}$ apresentam um crescimento ósseo semelhante ao observados em gaps menores ${ }^{21}$.

Como descrito por alguns autores ${ }^{15-18,20,22}$, no processo de reparação tecidual, as membranas têm a função de prevenir a migração e ação dos fibroblastos e promovem uma melhor vascularização, estabilização, além de proporcionarem espaço para crescimento ósseo 
e concentrarem fatores que estimulam o crescimento local, sendo assim fonte de células osteogênicas.

\section{Conclusão}

Através deste relato de caso concluiu-se que a utilização da membrana não reabsorvível de polipropileno (Bone Heal®) contribui para a preservação do coágulo dentro do alvéolo após a exodontia, dando manutenção as formas dos rebordos alveolares e promovendo assim regeneração óssea guiada.

Pôde se concluir, também, que os gaps no sentido horizontal presentes após a instalação do implante de forma imediata, após a extração cirúrgica, se forem menores ou iguais a 3mm, irão cicatrizar com total preenchimento ósseo, entretanto, se estes forem maiores que $3 \mathrm{~mm}$, necessitará do uso de enxerto ósseo e/ou membrana, para promover a cicatrização óssea. No presente relato porém, o gap era maior que $4 \mathrm{~mm}$, e ainda assim observou-se crescimento ósseo.

Sempre que cabível a instalação do implante imediatamente após a extração deve ser indicada, uma vez que esta irá preservar a estrutura óssea da região, além de manter a arquitetura gengival e reabilitar o paciente.

A instalação do implante nesse tipo de situação apresenta um bom prognóstico e uma elevada taxa de sucesso.

\section{Referências}

1. Zani SR, Alves RA, Korb SHB, Rivaldo EG, Frascal LCF. Colocação de implante imediato após exodontia: relato de caso clínico. Odontol Clín -Cient. 2011:10(3);281-4.

2. El Haddad E, Lauritano D, Candotto V, Carinci F. Guided bone regeneration is a reliabletechnique in implant dentistry: An overview and a case report. OA Dentistry. 2014:2(1);5.

3. Ortega-Martínez J, Pérez-Pascual T, Mareque-Bueno S, Hernández-Alfaro F, Ferrés-Padró E. Immediate implants following tooth extraction. A systematic review. Med Oral Patol Oral Cir Bucal. 2012:17(2);251-61. 
4. Kubilius M, Kubilius R, Gleiznys A. The preservation of alveolar bone ridge during tooth extraction. Stomatologija, Baltic Dent and Max J. 2012:14(1);3-11.

5. Marchant MSH, Vivanco TMF. Provisionalización Inmediata en Alvéolo Fresco: dos casos clínicos em el sector anterossuperior. Ver Clin Periodoncia Implantol Rehábil Oral. 2009:2(1);1622.

6. Brescovitt RA, Thomé G, Melo ACM , Silva RD. Soft tissue behavior around dental implants placed in fresh extraction sockets and immediately restored in esthetic area: a preliminary shortterm evaluation. Rev odontol UNESP. 2017:46(4);196-02.

7. Tavarez RRJ, Reis WLM, Rocha AT, Firoozmand LM, Bandéca MC, Tonetto MR. Atraumatic extraction and immediate implant installation: The importance of maintaining the contour gingival tissues. J of Inter Oral Health. 2013:5(6);113-8.

8. Khan FR, Ali R, Nagi SE. A review of the failed cases of dental implants at a university hospital in Karachi, Pakistan. J Pak Med Assoc. 2016:66(10);24-26.

9. Guerrero MD, CID, Gonzalo , Oliva P. Evaluación de la Pérdida Osea y del Éxito / Fracaso de Implantes de Titanio de Posicionamiento Inmediato y Tardío con Carga Inmediata, Usados para Restauraciones de Arco Completo a 12 Meses de su Implantación. Int J Odontostomat. 2016:10(3);399-407.

10. Clementini M, Morlupi A, Agrestini C, Ottri L. Success rate of dental implants inserted in autologous bone graft regenerated areas: a systematic review. Oral \& Implant. 2011:3(4);3-10.

11. Mezzomo LA, Shinkai RS, Mardas N, Donos N. Alveolar ridge preservation after dental extraction and before implant placement: A literature review. Rev Odonto Cienc. 2011:26(1);77-83.

12. Primo BT, Fernandes EL, Lima PVP, Kramer PF. Implante imediato para substituição de elemento dentário com fratura radicular:relato de caso clínico. Stomatos. 2011:17(32);65-71.

13. Hoornaert A, d'Arros C, Heymann MF, Layrolle P. Biocompatibility, resorption and biofunctionality of a new synthetic biodegradable membrane for guided bone regeneration. Biomed Mater. 2016:11(1);1-12.

14. Zafiropoulos G, Kasaj A, Hoffmann O. immediate Implant Placement in Fresh Mandibular Molar Extraction Socket: 8-Year Results. A Case Report. J of Oral Implant.2010:36(2);145-51.

15. Salomão M, Siqueira JTT. Regeneração óssea guiada através de barreira exposta ao meio bucal após exodontias. Relato de caso. Rev Bras Implant. 2010:7(10);5-7.

16. Salomão M; Siqueira JTT, Alvarez FK. Regeneração óssea guiada em defeitos extensos pósexodontias utilizando membrana exposta ao meio bucal. Rev Implantnews. 2010:7(6);753-9.

17. Mazaro JVQ, Godoy PAL, Junior JFS, Mello CC, Pellizzer EP, Zavanelli AC. Regeneração óssea guiada em implantodontia - relato de caso. RFO. 2014:19(1);121-8. 
18. Liu J, Kerns DG. Mechanisms of Guided Bone Regeneration: A Review. Open Dent J. 2014:8(1);56-65.

19. Borges FL, Dias RO, Piattelli Al, Onuma T, Gouveia Cardoso LA, Salomão M, et al. Simultaneous Sinus Membrane Elevation and Dental Implant Placement Without Bone Graft:A 6-Month Followup Study. J Periodontol. 2011:82(3);403-12.

20. Zeppini LAS. Barreira de polipropileno-Uma nova abordagem para regeneração óssea guiada (ROG). Rev Odontologia (ATO). 2014:14(5);301-07.

21. Bartee BK. Osteogenics clinical education: implant site development and extration sitegrafting. Osteogenics Biomedical 2011: 45 [Online] Available from Internet. [cited 27-9-2018].

22. MUNIR, S \& SIQUEIRA, JTT. Uso da barreira de polipropileno pós exodontia. Relato de três casos clínicos. Rev Bras Implant. 2009, v. único, p. 12-15.

23. West JD, Oates TW. Identification of stability changes for immediately placed dental implants. Int J Oral Maxilofac Implants. 2007Jul-Aug; 22(4):623-30.

\section{Apêndice de Figuras}

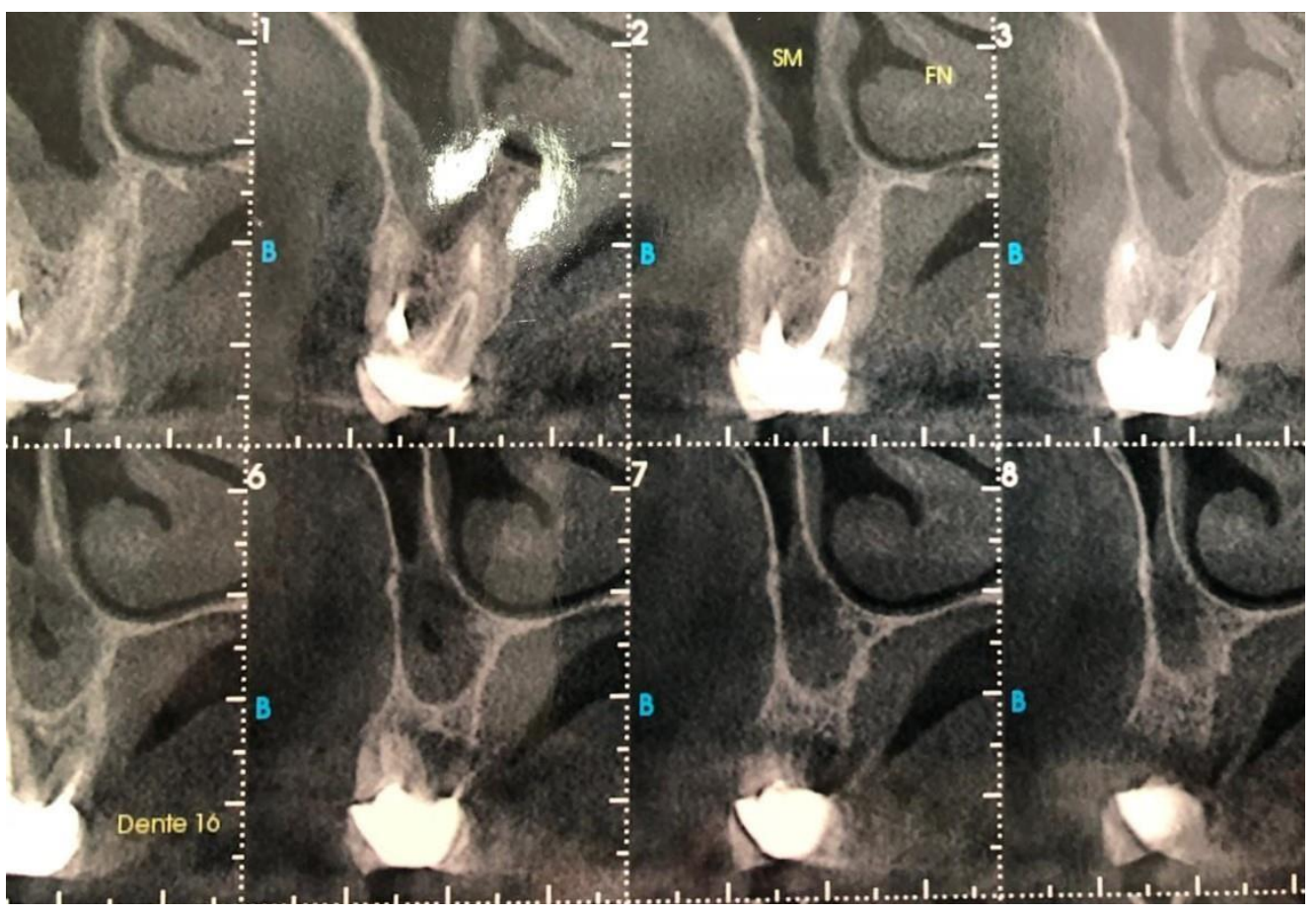

Figura 1 - Tomografia 


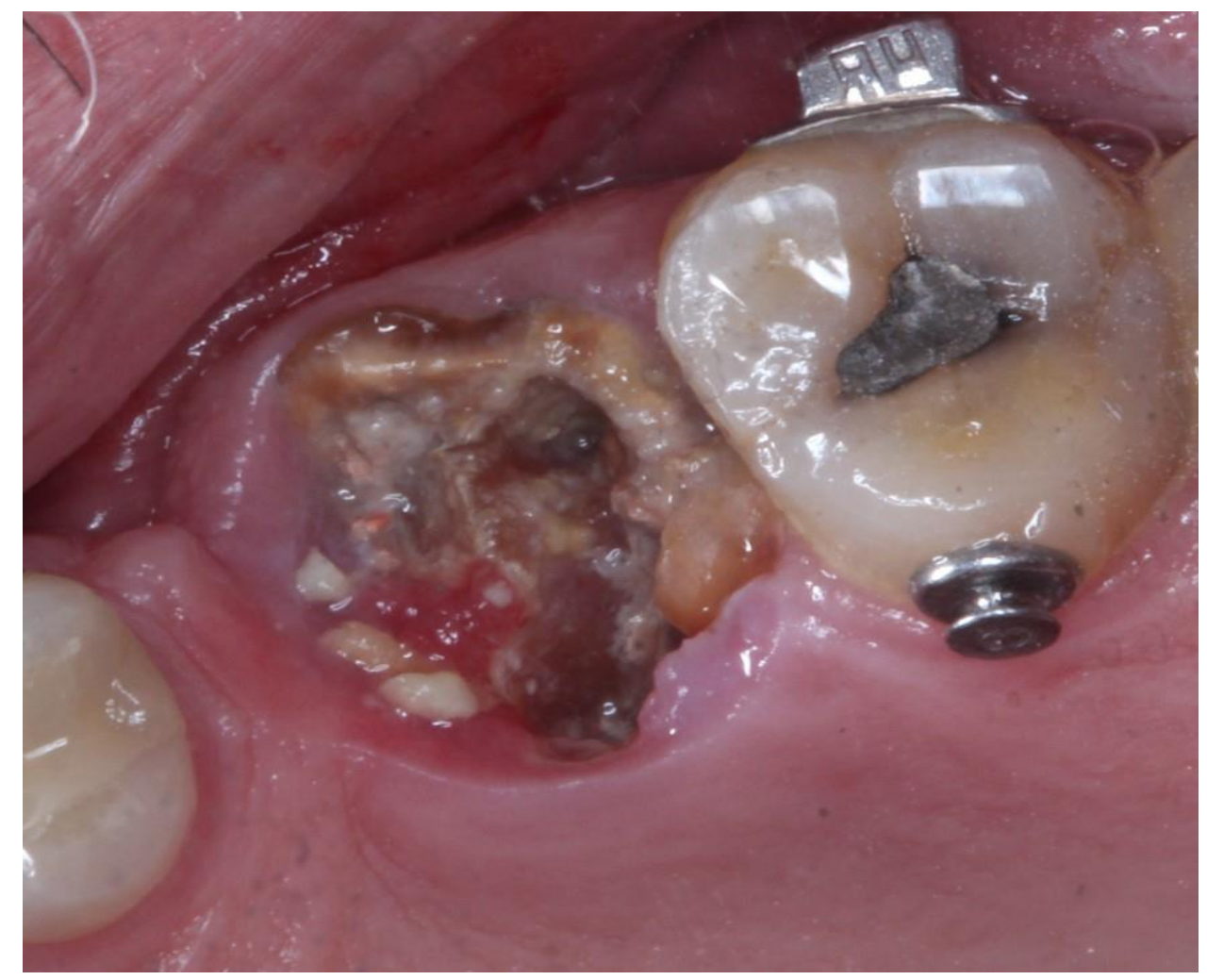

Figura 2 - Aspecto inicial

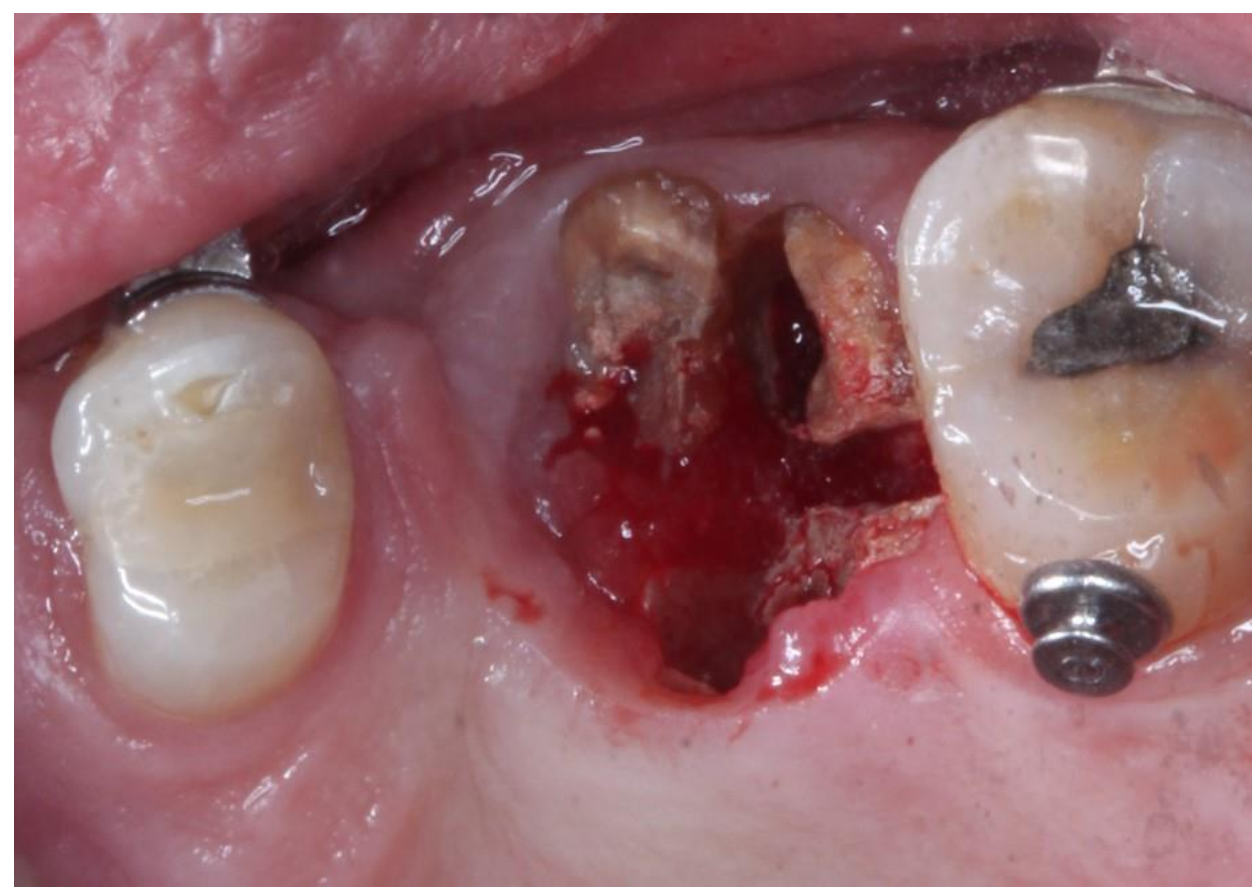

Figura 3 - Exodontia minimamente traumática do elemento 16 


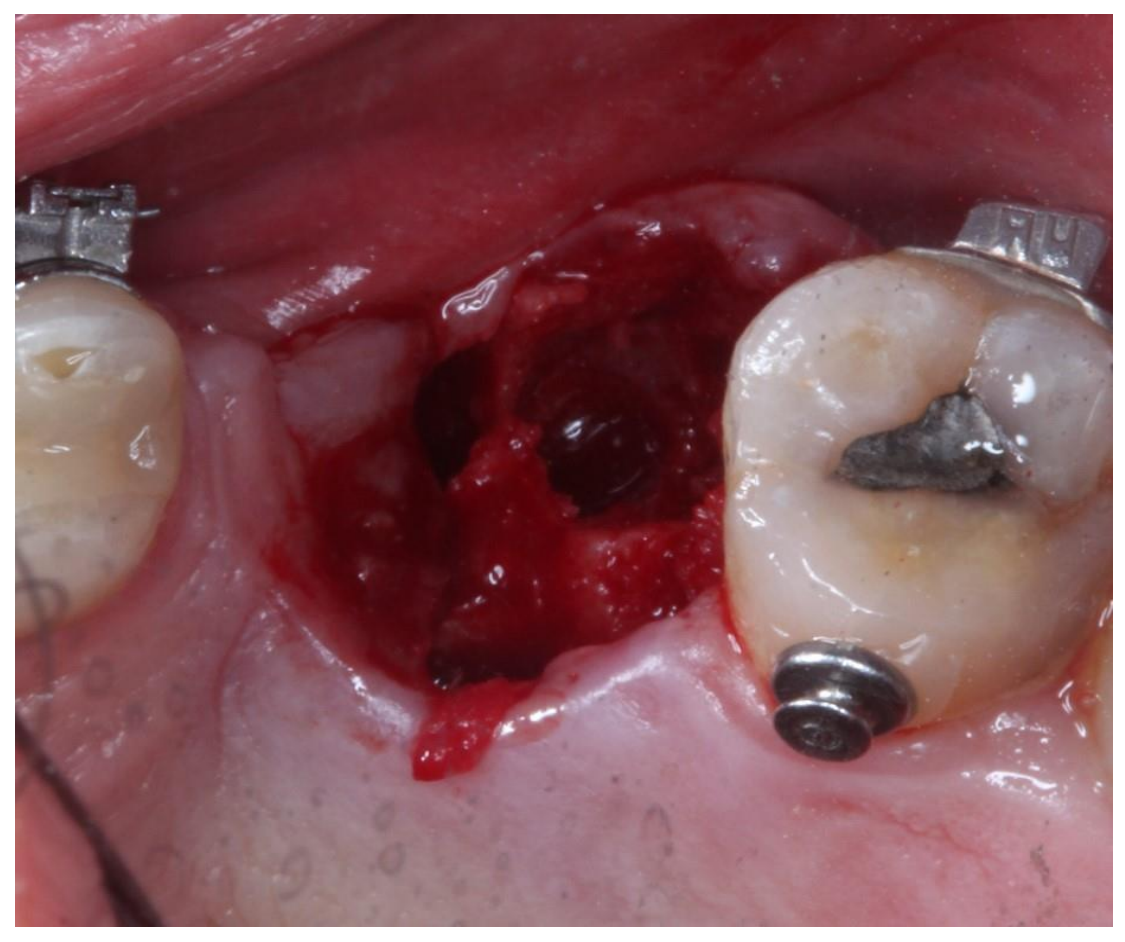

Figura 04 - Alvéolo pós - exodontia do elemento 16

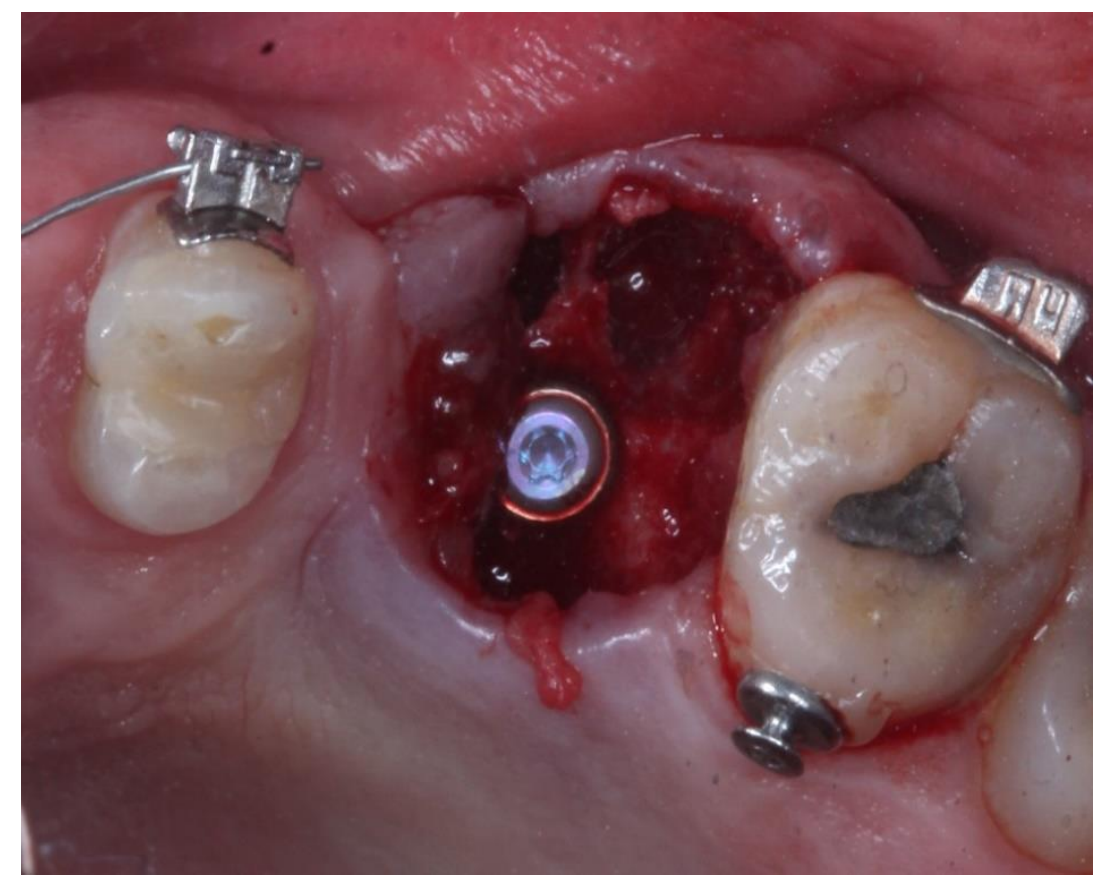

Figura 05 - Instalação do implante

1107 Id on Line Rev. Mult. Psic. V.12, N. 42, p. 1098-1109, 2018 - ISSN 1981-1179 Edição eletrônica em http://idonline.emnuvens.com.br/id 


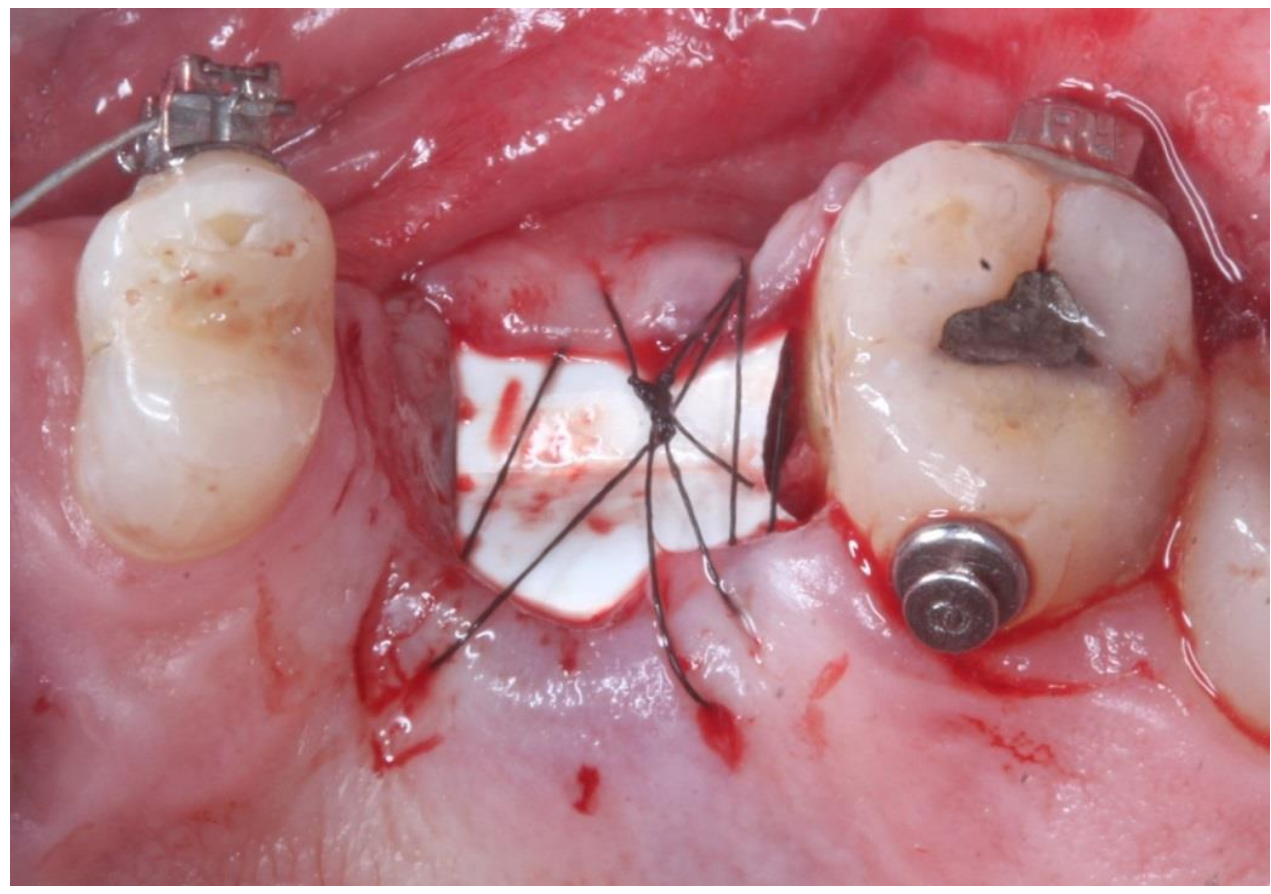

Figura 06 - Adaptação da barreia Bone Heal com sutura cuidadosa(de dentro para fora) para não deslocar

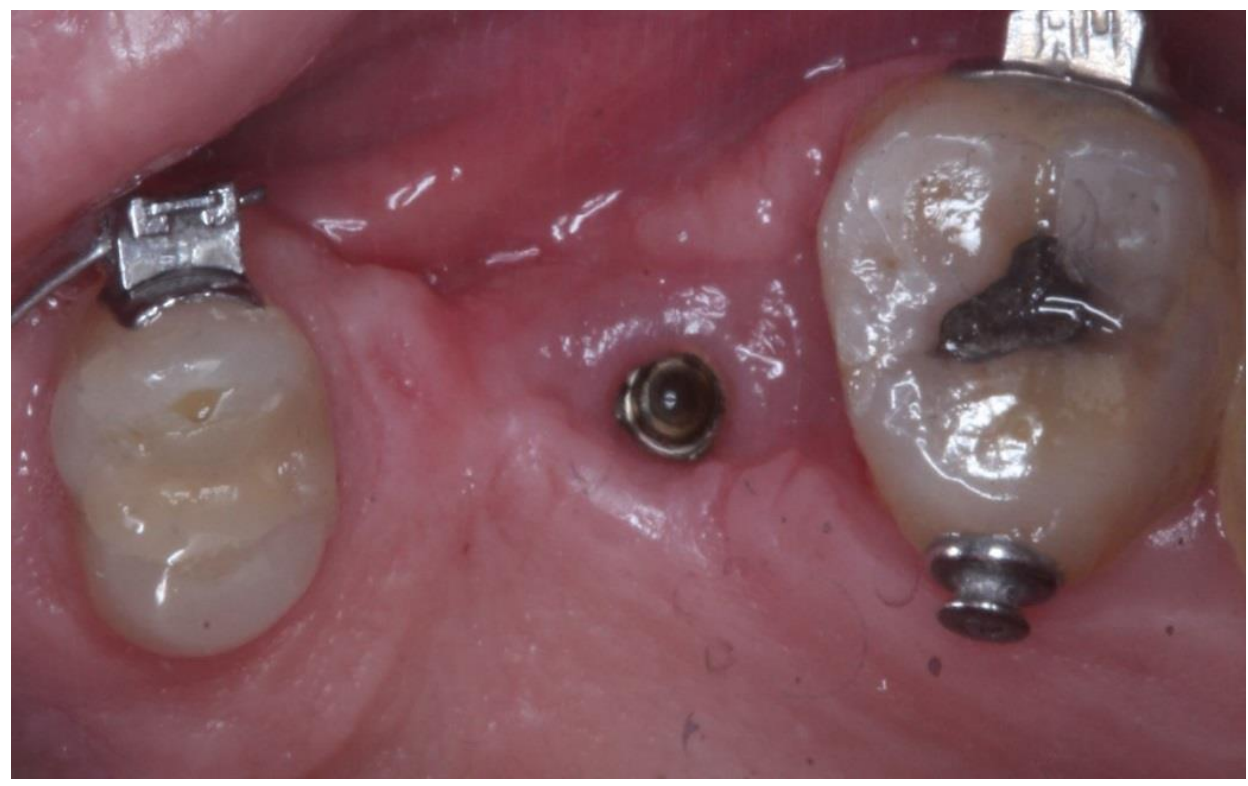

Figura 07 - 


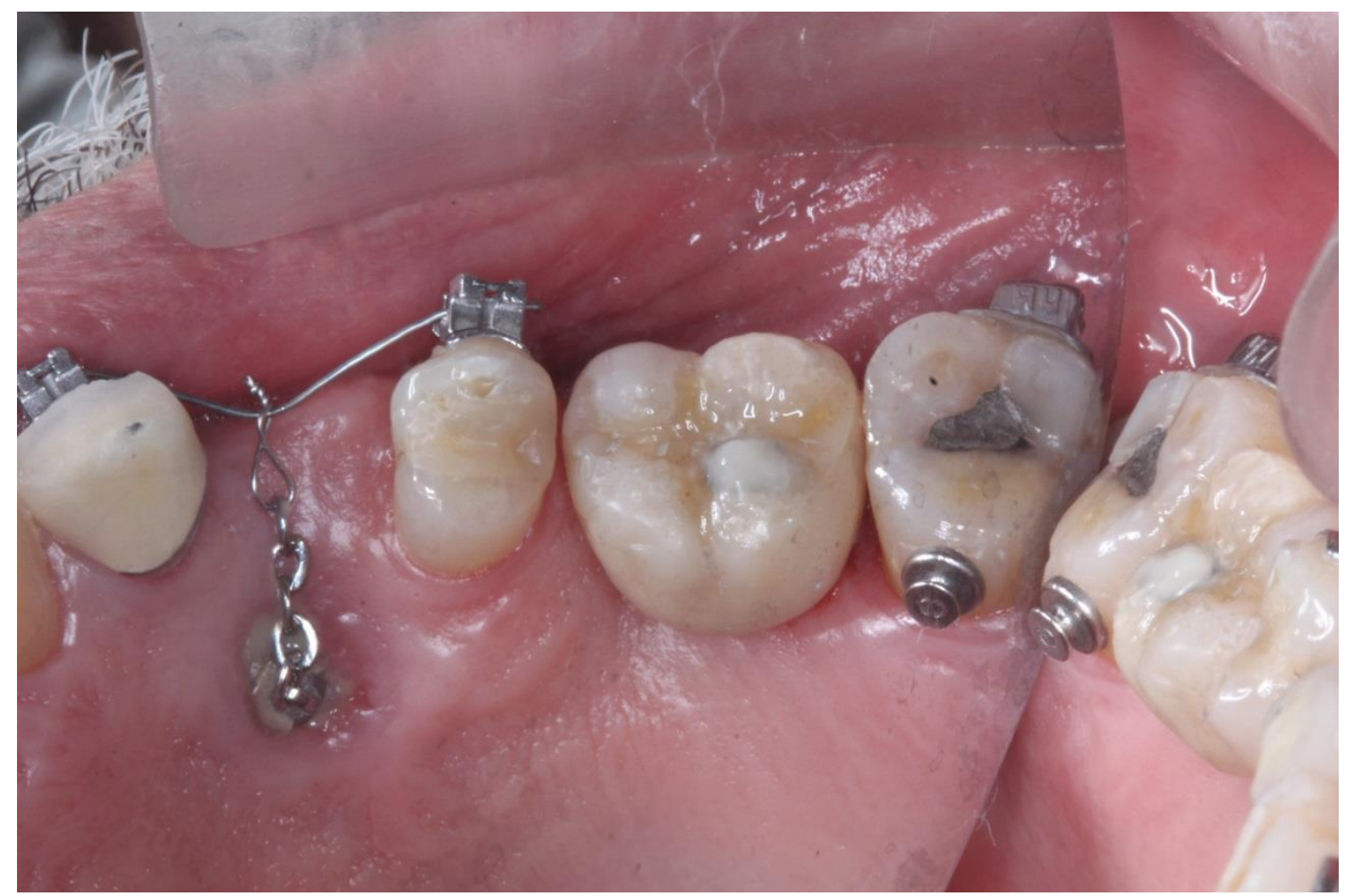

Figura 08 -

\section{Como citar este artigo (Formato ABNT):}

CAVESTRO, Thais de Oliveira; OLIVEIRA, Evan Novais de; SANTANA, Larissa Ledo Pereira. Implante imediato com uso da membrana de polipropileno: Relato de caso. Id on Line Rev.Mult. Psic., 2018, vol.12, n.42, p. 1098-1109. ISSN: 1981-1179.

Recebido: 25/06/2018;

Aceito: $29 / 10 / 2018$ 